\title{
Morpho-Physiological Characterization of Durum Wheat (Triticum durum L.) Genotypes under Irrigated Conditions
}

\author{
Himani $^{1 *}$, Shashi Madan ${ }^{1}$ and Renu Munjal ${ }^{2}$ \\ ${ }^{1}$ Department of Chemistry and Biochemistry, COBS\&H, CCS Haryana Agricultural \\ University, Hisar-125004, Haryana, India \\ ${ }^{1}$ Department of Genetics and Pant Breeding, COA, CCS Haryana Agricultural University, \\ Hisar-125004, Haryana, India \\ *Corresponding author
}

A B S T R A C T

\begin{tabular}{|l|}
\hline K e y w o r d s \\
$\begin{array}{l}\text { Durum wheat, Flag leaf } \\
\text { area, Morphological } \\
\text { parameters, Plant height, } \\
\text { Specific leaf weight }\end{array}$ \\
\hline Article Info \\
\hline $\begin{array}{l}\text { Accepted: } \\
\text { 20 January } 2018 \\
\text { Available Online: } \\
\text { 10 February } 2018\end{array}$ \\
\hline
\end{tabular}

\section{Introduction}

Durum wheat (Triticum durum L.) is the only tetraploid (AABB, $2 n=4 x=28$ ) wheat species of commercial importance which is widely cultivated across the country. Furthermore, the crop's agronomic adaptability is another aspect that attracts farmers to grow widely. An efficient improvement of the crop depends on the association of grain yield with yield components. The nutritional quality of wheat relies on several morphological, physiochemical and biochemical components. Wheat grain yield is the major end product of the interaction of a large number of physiological and biochemical processes occurring throughout the growing cycle.

Quality is an important aspect of durum wheat and it demands specific quality traits as well as functionality. Morphological and agronomic characters of wheat have a special role in determining the importance of each trait in increasing yield, so these traits are used in breeding programs which at least led to improving yield and introducing commercial varieties (Mollasadeghi et al., 2011). Successful breeding of new and high yielding 
varieties depends on the yield contributing morphological traits and choosing small number of important traits having positive correlation (Nawaz et al., 2013). Flag leaf area and plant height are an important morphological yield contributing traits and positively correlated with yield per plant. Specific leaf weight could provide a practical way for plant breeders to evaluate photosynthate source-sink relationship. It has been investigated that leaves being the site of photosynthetic activity, appear to have an obvious relationship to the plant's grain yield ability.

Compared to other leaves, the flag leaf contributes the most photosynthetic assimilates in wheat therefore it assumes the greatest importance in terms of grain yield. Since the flag leaf plays a predominant role, its size is likely to be important. The plant height confers to the plant a better capacity to tolerate the dryness (Ben-Abdallah and BenSalem, 1993).

\section{Materials and Methods}

In present study, grains of 36 durum wheat genotypes including four checks (two bread and two durum wheat) were procured from Wheat and Barley Section, Department of Genetics and Plant Breeding. The crop was raised in randomized Block Design (RBD) in a plot size of $6 \times 1.20$ sq. meter. The observations for morphological parameters were recorded in leaf samples at the heading stage. At heading stage three flag leaves per accession were excised and immediately brought to the laboratory. The flag leaf area (in $\mathrm{cm} 2$ ) was then determined using an area meter (LI-3000, Li-Cor, Lambda Instruments Co., USA). Specific leaf weight was estimated by dried the flag leaf in an oven at $65^{\circ} \mathrm{C}$ for 72 hours and dry weight was recorded. Specific leaf weight was calculated using the following formula: Leaf dry weight (g)/Specific leaf weight $\left(\mathrm{g} / \mathrm{cm}^{2}\right)=$ Total leaf area $\left(\mathrm{cm}^{2}\right)$. Plant height was measured at the time of maturity. The plant height from the ground level to the top of spikes excluding awns was recorded in centimeters.

\section{Statistical analysis}

The experimental data were analyzed using analysis of variance for the complete randomized design (CRD) where each observation was replicated thrice. To compare the treatments, critical difference $(\mathrm{P}=0.05)$ was calculated. The correlation coefficient was calculated according to the formula suggested by Pearson.

\section{Results and Discussion}

During grain filling stage photosynthesis is mainly depends on photosynthetic activity and green leaf area duration (Hafsi et al., 2000) however, this trait is in general difficult to measure precisely as it is highly influenced by environmental factors such as temperature, soil type and amount of rainfall (Masood et al., 2005). Figure 1 exhibits the flag leaf area of durum wheat genotypes. Among the thirty six genotypes evaluated flag leaf area ranged from 35.65 to $97.31 \mathrm{~cm}^{2}$ with an overall mean value of $59.20 \mathrm{~cm}^{2}$. The superior genotypes found for this trait were HD $4730\left(97.31 \mathrm{~cm}^{2}\right)$ followed by PDW $337\left(95.19 \mathrm{~cm}^{2}\right)$ while the genotype HI $8748\left(35.65 \mathrm{~cm}^{2}\right)$ had minimum value. The variation in flag leaf area among genotypes was quite evident; however an increased flag leaf area could be reasoned to the increased chlorophyll content which is responsible for more photosynthetic activities with high capacity to store assimilative products and to translocate into developing grains thereby increasing their weight. Riaz and Chowdhry (2003) studied six wheat genotypes viz. 90-R-34, 96-R-37, Rawal 87, Rohtas 90, Chakwas 86, and Kohsar 96 for some economic traits. 
Fig.1 Flag leaf area $\left(\mathrm{cm}^{2}\right)$ in durum wheat genotypes

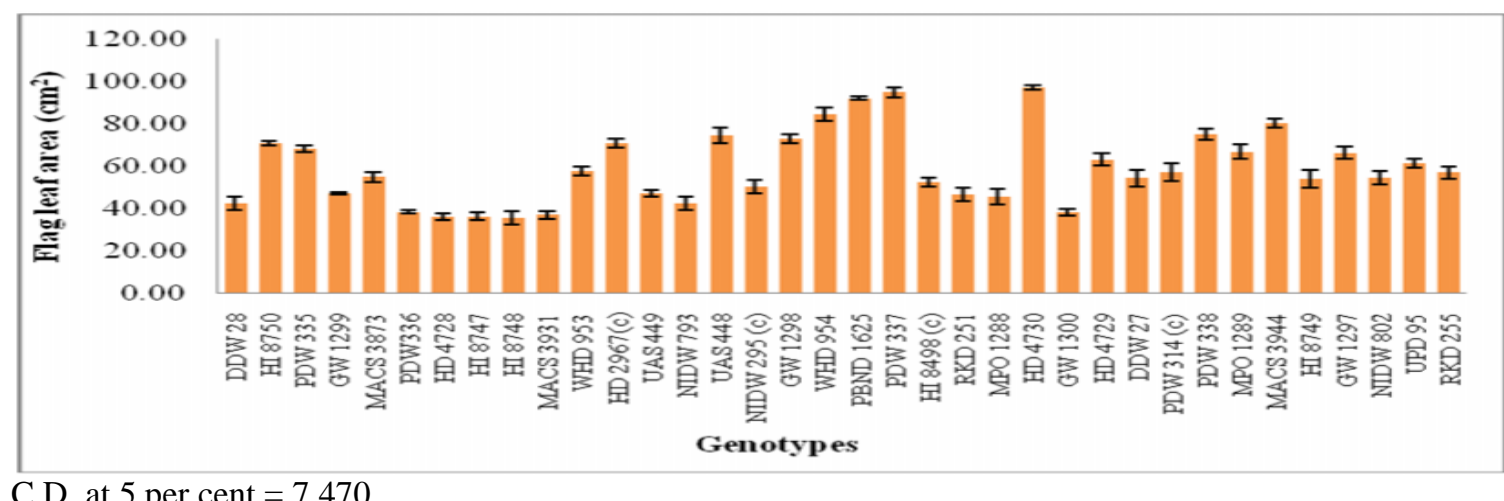

C.D. at 5 per cent $=7.470$

Fig.2 Specific leaf weight $\left(\mathrm{g} / \mathrm{cm}^{2}\right)$ in durum wheat genotypes

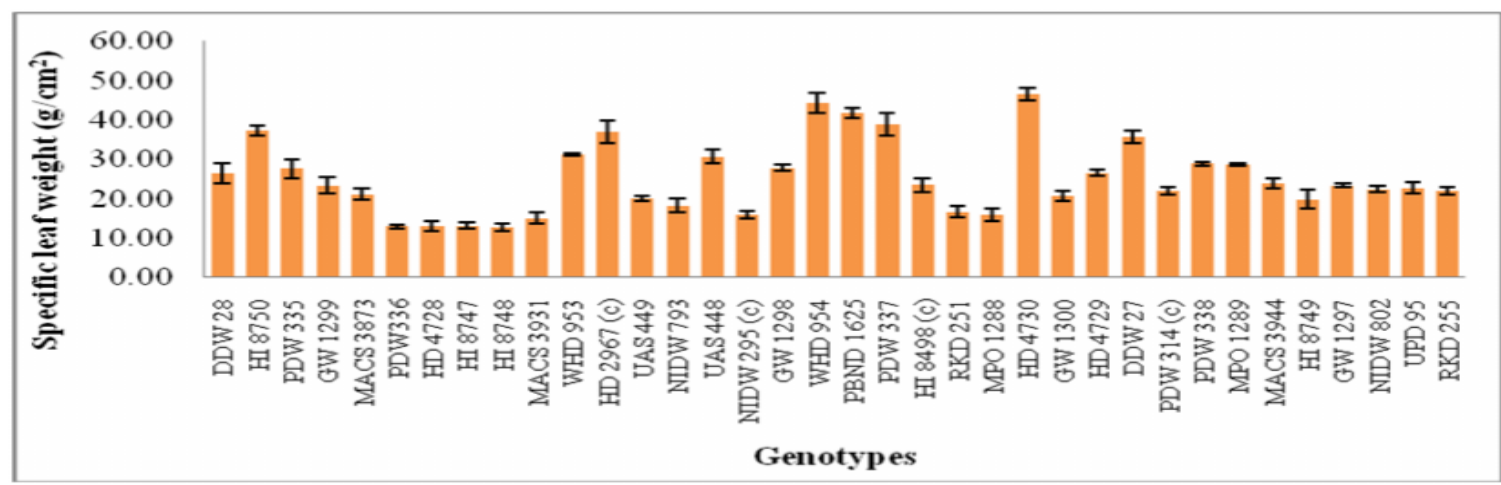

C.D. at 5 per cent $=4.373$

Fig.3 Plant height $(\mathrm{cm})$ in durum wheat genotypes

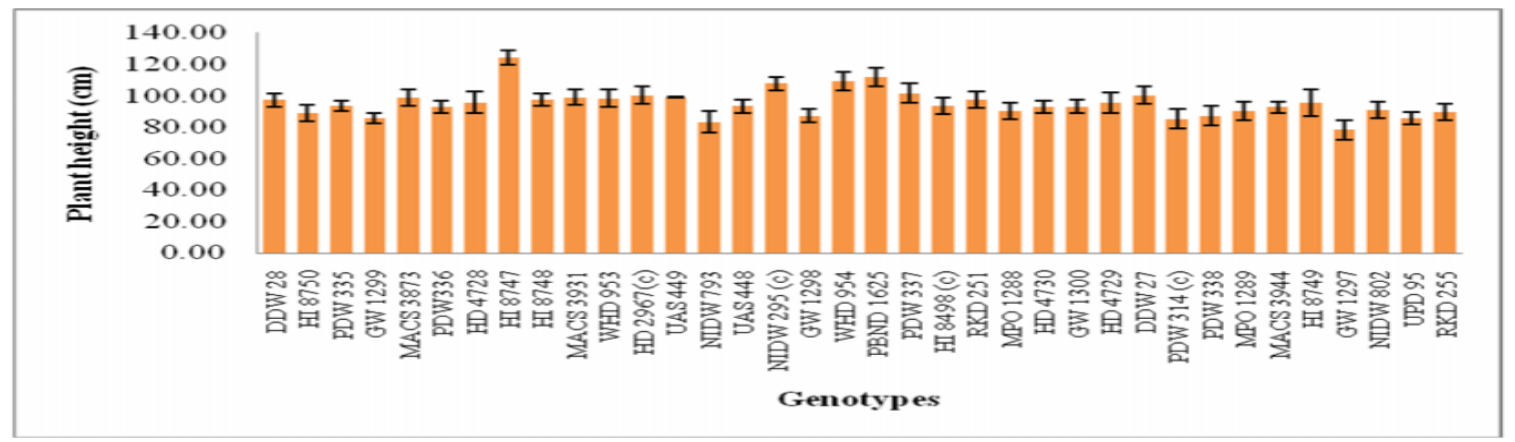

C.D. at 5 per cent $=14.738$

These were crossed in $6 \times 6$ full diallel fashions to determine the genetic architecture of some economic traits of wheat under drought condition. They found that the genotypes differed significantly among each other for all the traits studied. It was revealed that flag leaf area was conditioned by over-dominance type of gene action and plant height results from the interaction of genotype and environment and it ranged from $82.6-107.5 \mathrm{~cm}$ and this concluded that there was a direct relationship of flag leaf area with grain yield. Sahin and Yildirim (2006) studied the inheritance of grain yield per plant, flag leaf width, and flag leaf length, applying 
Jinks-Hayman diallel analysis in an $8 \times 8$ wheat cross population involving the bread wheat $(T$. aestivum L.) genotypes. Studies revealed that the large flag leaf provides the maximum amount of photosynthetic assimilates to be stored in the grains which will eventually help to increase photosynthetic efficiency by increasing the production of photosynthesis which is then translocated into grains and increased their weight. The flag leaf area and its active duration during grain filling had been considered as an essential trait in determining the grain yield (Khaliq et al., 2008). Guendouz et al., (2012) studied 10 genotypes of durum wheat (Triticum durum Desf.) genotypes and observed that flag leaf photosynthesis in wheat contributed about 30-50 per cent of the assimilates for grain filling and initiation of grain filling coincides with the onset of senescence, therefore, photosynthesis of flag leaf was the most important basis of the formation of grain yield. Khan et al., (2012) conducted an experiment on Triticum aestivum by applying mixed inheritance analysis for flag leaf area and concluded that one to two major genes and polygenes/minor genes in cumulative manner were involved in controlling the flag leaf area and said that flag leaf area was an important parameter for determining differences in dry weight yield and grain yield.

The significant variation in specific leaf weight was due to enhanced photosynthate translocation efficiency which is a function of leaf dry matter content (Semcheddine and Hafsi, 2014). Specific leaf weight $\left(\mathrm{g} / \mathrm{cm}^{2}\right)$ of durum wheat genotypes is depicted in Figure 2. It varied from $12.85-46-54 \mathrm{~g} / \mathrm{cm}^{2}$ with an overall mean value of $25.24 \mathrm{~g} / \mathrm{cm}^{2}$. The highest value was observed in HD $4730\left(46.54 \mathrm{~g} / \mathrm{cm}^{2}\right)$ genotype followed by WHD $954\left(44.30 \mathrm{~g} / \mathrm{cm}^{2}\right)$ and lowest value was observed in HI 8748 $\left(012.85 \mathrm{~g} / \mathrm{cm}^{2}\right)$. These observations indicate that higher the photosynthesis higher will be the accumulation in leaves. Similar kinds of results were also reported by Singh and Rajan (2009). Semcheddine and Hafsi (2014) conducted an experiment on 10 durum wheat (Triticum durum Desf.) genotypes under rainfed conditions of
Eastern Algeria and measured grain yield and its components, heading evolution, leaf relative water content, leaf specific weight, grain filling rate and duration and chlorophyll content. It was observed that specific leaf weight differed significantly among water treatments at heading and grain filling stages suggesting the possibility of selecting tolerant genotypes for drought tolerance under semi-arid condition.

The plant height is important in terms of resistance to lodging and harvest index (Dogan, 2009). The plant height excels in capacity so as to support panicle growth by large stem reserve mobilization (Sourour et al., 2010) Figure 3 depicts the plant height $(\mathrm{cm})$ in durum genotypes. The range of plant height was 78.33 to $124.0 \mathrm{~cm}$ with an overall mean value of $95.07 \mathrm{~cm}$. The genotypes with maximum value for plant height were HI $8747(124.0 \mathrm{~cm})$ followed by PBND $1625(111.67 \mathrm{~cm})$ and lowest was found in GW $1297(78.33 \mathrm{~cm})$. Since the ideal plant height ranges from 90 to $100 \mathrm{~cm}$ (Khan et al., 2013). Kahrizi et al., (2010) conducted studies on 18 experimental durum wheat and two checks under rain-fed condition to estimate the genetic variability parameters and relationship among 11 agrophysiological traits and results revealed that the plant height ranged from 52.70 to $96.05 \mathrm{~cm}$ and it had a positive significant effect on yield components. Sourour et al., (2010) conducted an experiment on local collection of 30 Tunisian durum wheat (Triticum durum) landraces to evaluate the agronomical traits and reported that flag leaf area is an important trait to be considered because of its contribution to photosynthetic activities and it ranged from 22.61 to $44.28 \mathrm{~cm}^{2}$ and the plant height ranged from 88.2 to $157 \mathrm{~cm}$. Nawaz et al., (2013) evaluated 25 wheat varieties for various morphological and yield related traits and found that flag leaf area ranged from 29.96 to 57.17 $\mathrm{cm}^{2}$ and plant height ranged from 73.26 to $99.11 \mathrm{~cm}$. Therefore, present study indicates that these traits may be used in breeding programs which at least led to improving yield and introducing commercial varieties. 


\section{References}

Ben-Abdallah N Ben Salem M (1993). Paramètres morpho physiologiques desélection pour la résistance à la sécheresse. In: Tolérance à la sécheresse des céréales en zone méditerranéenne. Diversité génétique et amélioration variétale (Ed INRA, Paris). pp. 253-264.

Guendouz A Maamari K Guessoum S Hafsi M Benidir M (2012). Flag leaf senescence, chlorophyll content and its realtionships with yield components under drought in durum (Triticum durum Desf.). Int $\mathbf{J}$ Innovations Bio-Sci 2(4): 186-192.

Hafsi M Mechmeche W Bouamama L Djekoune A Zaharieva M Monneveux P (2000). Flag leaf senescence, as evaluated by numerical image analysis, and its relationship with yield under drought in durum wheat. J Agron Crop Sci 185: 275-280.

Kahrizi D Cheghamirza K Kakeai M Mohammadi R Ebadi A (2010). Heritability and genetic gain of some morphophysiological variables of durum wheat (Triticum turgidum var. durum). Afr J Biotechnol 9(30): 4687-469.

Khaliq I Irshad A Arshad M (2008). Awn and flag leaf contribution towards grains yield in spring wheat (Triticum aestivum L.). Cereal Res Commun 36(1): 65-76.

Khan AA Alam MA Alam MK Alam MJ Sarker ZI (2013). Correlation and path analysis of durum wheat (Triticum turgidum L. var. durum). Bangladesh J Agril Res 38(3): 515-521.

Khan, M.I., Khattak, G.S.S., Khan, A.J., Subhan, F., Mohammad, T. and Ali, A. 2012. Genetic control of flag leaf area in wheat (Triticum aestivum) crosses. Afr $\mathbf{J}$ Agric Res 7(27): 3978-3990.

Masood S Javaid A Rabbani A Anwar R (2005). Phenotypic diversity and trait association in bread wheat (Triticum aestivum L.) landraces from Baluchistan. Pak. J. Bot. 37: 949-957.

Mollasadeghi V Imani AA Shahryari R Khayatnezhad M (2011). Classifying bread wheat genotypes by multivariable statistical analysis to achieve high yield under after anthesis drought. Mid East J Scientific Res 7(2): 217-220.

Nawaz R Inamullah Ahamd H Din SU Iqbal MS (2013). Agromorphological studies of local wheat varieties for variability and their association with yield related traits. Pak J Bot 45(5): 1701-1706.

Riaz R Chowdhry MA (2003). Genetic analysis of some economic traits of wheat under drought condition. Asian J Plant Sci 2: 790-796.

Sahin D Yildirim MB (2006). Inheritance of grain yield per plant, flag leaf width, and length in an $8 \times 8$ diallel cross population of bread wheat (Triticim aestivum L.). Turk J Agric For 30: 339-345.

Semcheddine N Hafsi M (2014). Effect of supplementary irrigation on agronomical and physiological traits in durum wheat (Triticum durum Desf.) genotypes. J Agric Sci 6(9): 184-197.

Singh VK Rajan S (2009). Changes in photosynthetic rate, specific leaf weight and sugar contents in mango (Mangifera indica L.). Open Hortic J 2:40-43.

Sourour A Chahine K Youssef T Olfa SA and Hajer SA (2010). Phenotypic diversity of Tunisian durum wheat landraces. Afr Crop Sci J 18(1): 35-42.

\section{How to cite this article:}

Himani, Shashi Madan and Renu Munjal. 2018. Morpho-Physiological Characterization of Durum Wheat (Triticum durum L.) Genotypes under Irrigated Conditions. Int.J.Curr.Microbiol.App.Sci. 7(02): 2350-2354. doi: https://doi.org/10.20546/ijcmas.2018.702.286 